\title{
I. On the spontaneous evolution of sulphuretted hydrogen in the waters of the western coast of Africa, and of other localities
}

\section{J. Frederic Daniell}

To cite this article: J. Frederic Daniell (1841) I. On the spontaneous evolution of sulphuretted hydrogen in the waters of the western coast of Africa, and of other localities, Philosophical Magazine Series 3, 19:121, 1-19, DOI: 10.1080/14786444108650356

To link to this article: http://dx.doi.org/10.1080/14786444108650356

曲 Published online: 01 Jun 2009.

Submit your article to this journal $[\pi$

Џll Article views: 2

Q View related articles ¿ 


\section{PHILOSOPH ICAL MAGAZINE}

A N I

\section{JOURNAL OF SCIENCE.}

\section{[THIRD SERIES.]}

\section{JUL Y 184.1.}

I. On the Spontaneous Evolution of Sulphuretted Hydrogen in the Waters of the Western Coast of Africu, and of other Localities. By J. Frederic Danield, For, Sec. R.S., Prof. Chem. in King's Coll., London, \&c.*

$\mathrm{M}^{\mathrm{Y}}$

$\mathrm{Y}$ attention was first directed to the subject, which I shall have the honour of submitting to your notice this evening, by the Lords of the Admiralty, in April 1840, who sent me eight specimens, and afterwards two additional specimens, of water from the mouths of the rivers on the western coast of Africa, with directions to analyze them, for the purpose of discovering, if possible, the cause of the rapid decay of the copper-sheathing of ships employed upon those stations.

Of the comparative duration of the metal in the vessels of the Royal Navy I have not been informed; but the evil complained of is well known also in the merchant service; and upon inquiry of one of the largest copper-smelters in South Wales, he assures me, that " the experience of between thirty and forty years has led his mind to the conclusion that sheathing copper will be as much or more injured on a nine months' voyage to and along the coast of Africa, as by the wear of from three to four years on any other trade."

The first water which I examined was from the river at Sierra Leone, taken at three miles from the mouth. Upon drawing the cork of the bottle it was found to smell very strongly of sulphuretted hydrogen.

* Communicated by the Author; being the substance of a Lecture delivered to the Members of the Royal Institution on the 21st May, 1841.

Phil. Mag. S. 3. Vol. 19. No. 121. July 1841. 
The first idea which occurred to me was that which seems generally to have prevailed upon similar occasions, viz. that this gas was generated from some change which had taken place in the water after it had been bottled, from the decomposition of some animal or vegetable substance; but a little consideration showed that this explanation was quite inadmissible, inasmuch as the sediment from the whole bottle did not exceed half a grain, the water being perfectly bright, and the salts upon evaporation snow-white; and the water became perfectly sweet a very short time after it had been exposed to the air.

Indeed the common prejudice regarding the unlimited quantity of sulphuretted hydrogen generated by putrescence is perfectly untenable, and is founded solely upon its disagreeable odour. The fact is, that the quantity of sulphur in animal matter is very small, and the nauseous smell is by no means an infallible criterion of the existence of the gas.

As a natural product, sulphuretted hydrogen has hitherto been known chiefly as an ingredient in certain mineral waters, such as those of Harrowgate and Aix la Chapelle; the former of which contains, per gallon, 18.4 cub. in., the latter 44.0. The comparatively small springs which yield these waters are most carefully preserved by their proprietors, on account of their medicinal virtues, and the profits which are derived from their use.

The generation of the gas with which such waters are impregnated, has been usually attributed to some unknown action upon pyrites and other sulphurets of the metals in the interior of the earth, and it is pretty generally ascribed to volcanic action. It has also been generally known that sulphuretted hydrogen is produced by processes of decayor fermentation, in which large quantities of animal matters are concerned.

To the natural sources of this gas must now be added the estuaries of many large rivers and immense tracts of the Ocean in their immediate vicinity.

The results of the analysis of the African waters, sent to me from the Admiralty, embracing an extent of fifteen or sixteen degrees of latitude, are as follows :-

Each bottle was properly corked and sealed, and contained about three imperial pints; the water in all was perfectly bright, and had deposited very little sediment.

The first which I examined was labelled, "Water from the river at Sierra Leone, taken at three miles from the mouth, by Her Majesty's brigantine Dolphin, at low water, spring tides, on the 24th day of September, 1839, during the rainy season.

"Edward Holland, Lieut.-Com." 
Upon drawing the cork of this bottle, it was found to smell very strongly of sulphuretted hydrogen. The sediment in the bottle only amounted to 0.5 grain of vegetable matter. Specific gravity to $1018 \cdot 5$. The results of the analysis, calculated for the imperial gallon:

Sulphuretted hydrogen. $6 \cdot 18$ cub. in.

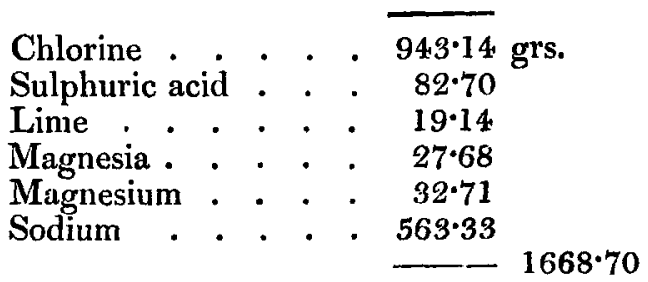

There was also a trace of potassa in this water.

The actual amount of dry salts obtained by evaporation, was $1696^{\circ} 0$ grains. The difference between this and the results of the analysis is not more than usual in similar cases, and arises from the impossibility of determining the exact mode in which the several acids and bases are combined in the water, and from the difficulty of drying the salts without the decomposition of a portion, at least, of some of them.

2. "Water from the river Volta, taken [at sea] twenty-eight miles from the mouth, bearing W.N.W., by Her Majesty's schooner Fair Rosamond, latitude $5^{\circ} 37^{\prime}$ north, longitude $1^{\circ} 10^{\prime}$ east, on the 4th of September, 1839; season not rainy."

This water also smelt very strongly of sulphuretted hydrogen; the sediment in the bottle did not exceed 0.3 grain of vegetable matter. It contained, per gallon,

Sulphuretted hydrogen . . . - 6.99 cub.in.

Chlorine . . . . . . . . . $\overline{1411 \cdot 68} \mathrm{grs}$.

Sulphuric acid . . . . . . . . 92477

Lime . . . . . . . . . . 14.75

Magnesia . . . . . . . . 35.70

Magnesium . . . . . . . . . $12 \cdot 46$

Sodium . . . . . . . . . . 916.20

Potassium . . . . . . . . . a trace

$24.83 \cdot 26$

Specific gravity, $1025^{\circ}$

Amount of salts from evaporation $.2480^{\circ} 0$

3. "Water from the river Bonny, taken at anchor off the B 2 
town in the river, by Her Majesty's schooner Fair Rosamond, on the 9th of October, 1839, about the conclusion of the rainy season."

This water smelt slightly of sulphuretted hydrogen, and the sediment in the bottle weighed only 0.4 grains, and consisted of vegetable matter. The results of the analysis were, per gallon,

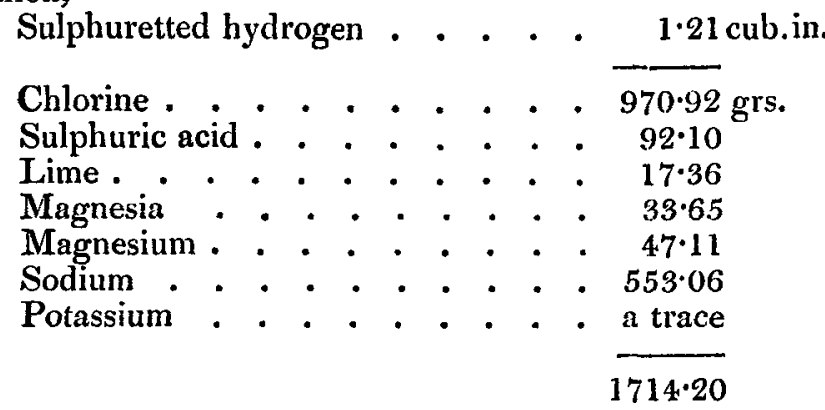

Amount of salts from evaporation . Specific gravity, 1019.0.

4. "Water from the river Mooney, which empties itself in the north-east part of Corisco Bay, taken from about a mile inside the mouth, by Her Majesty's brig Nautilus, September 4th, 1839. Rain had fallen, but the rainy season cannot be considered to have set in."

This water did not smell of sulphuretted hydrogen, nor did it afford any trace of that gas upon analysis ; the total amount of sediment in the bottle did not exceed $0 \cdot 1$ grain. It contained, per gallon,

$$
\begin{aligned}
& \text { Chlorine . . . . . . . . } 1184.11 \mathrm{grs} . \\
& \text { Sulphuric acid . . . . . . . . } 10980 \\
& \text { Lime . . . . . . . . . 14.17 } \\
& \text { Magnesia . . . . . . . . . } 44.78 \\
& \text { Magnesium . . . . . . . . 28.54 } \\
& \text { Sodium . . . . . . . } 732.32 \\
& \text { Potassium . . . . . . . a trace } \\
& 2113 \cdot 72
\end{aligned}
$$

Amount of salts from evaporation . 2104

Specific gravity, $1022 \cdot 5$.

5. "Water from the river Gaboon, taken at four miles above Parrot and Konicky Island [eight miles up the river], by Her Majesty's brig Nautilus, September 10th, 1839. Rain 
had fallen, but the rainy season was not considered to have set in. Latitude $0^{\circ} 15^{\prime}$ north, longitude $9^{\circ} 33^{\prime}$ east."

This water afforded no traces of sulphuretted hydrogen. The sediment in the bottle weighed 0.2 grain.

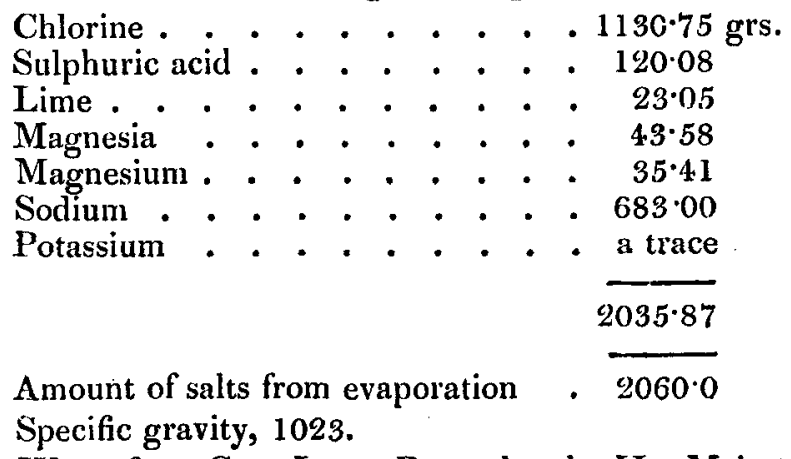

6. "Water from Cape Lopez Bay, taken by Her Majesty's brig Nautilus, September 28th, 1839, when the Cape bore W. by N. about ten miles. The rainy season had commenced."

This water smelt very strongly of sulphuretted hydrogen. The sediment in the bottle weighed only 0.1 grain, and consisted of vegetable matter. It contained, per gallon,

Sulphuretted hydrogen . . . . 11.69 cub.in,

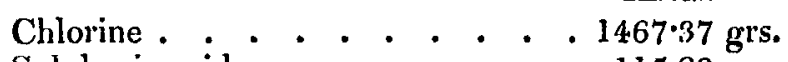

Sulphuric acid . . . . . . . 11520

Lime . . . . . . . . . 23.21

Magnesia . . . . . . . . 41.02

Magnesium . . . . . . . . . 28.44

Sodium . . . . . . . . . 921.60

Potassium . . . . . . . . a trace

Iodine . . . . . . . . a trace

$2596 \cdot 84$

Amount of salts from evaporation $\quad .2576 .00$

Specific gravity, 1026.

7. "River Congo,- -water taken off Shark's Point, at the entrance of the river, by Her Majesty's sloop Wolverine, on the I I th of November, 1839, four days before the customary rains, but light rains having already taken place."

This water smelt very slightly of sulphuretted hydrogen. The sediment in the bottle weighed 0.4 grain, and consisted of vegetable matter. It contained, per gallon, 
Sulphuretted hydrogen . . . . 0.67 cub.in.

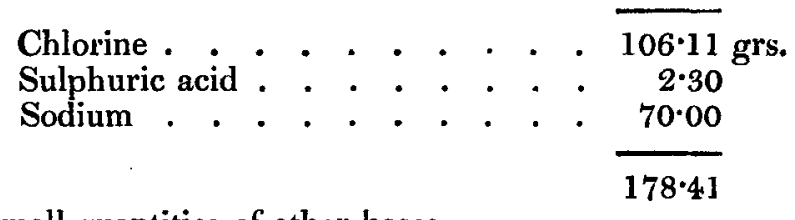

And small quantities of other bases.

Amount of salts from evaporation $\quad 188$

Specific gravity, $1002 \cdot 0$.

This is the only case in which the salts were discoloured by vegetable extractive matter.

8. "River Congo, - water taken about thirty-five miles up that river, by Her Majesty's sloop Wolverine, on the 11th of November, 1839, four days before the customary rains, but light rains having already taken place."

This water contained no sulphuretted hydrogen, and the sediment in the bottle was only 0.1 grain.

The amount of saline matter was only eight grains per gallon, and consisted of the chlorides of sodium, and magnesium, and sulphate of soda, chiefly.

Specific gravity $1000 \cdot 3$.

"Water from the river Bango, taken [at sea] at forty miles distance from the mouth, by Her Majesty's schooner Fair Rosamond, on the 26th of December, 1839, in latitude $8^{\circ} 33^{\prime}$ south, and longitude $12^{\circ} 4 l^{\prime}$ east." The water emitted a very strong smell of sulphuretted hydrogen. It was tolerably clear, but contained a little gelatinous matter which resembled spawn of fish. The sediment of the whole bottle, however, when dried, only weighed fifteen hundredths of a grain.

The results of the analysis, calculated for the imperial gallon, were as follows:-

Specific gravity, $1026 \cdot 4$.

Sulphuretted hydrogen, $4 \cdot 35 \mathrm{cub}$. in.

Dry salts, 2736 grs.

Consisting of chlorine 1513 , sulphuric acid 128, neutralized by bases, which have not yet been quantitatively determined, but consisting of sodium, magnesium, calcium, \&c.

"W Water taken by Her Majesty's schooner Fair Rosamond, off the Bango and Dande rivers, latitude $8^{\circ} 29^{\prime}$ south, longitude $12^{\circ} 33^{\text {T }}$ east, on the 29 th of December, 1839."

Results of analysis, - specific gravity, 1026.7.

There was no odour of sulphuretted hydrogen in this water, neither was any detected by tests. The quantity of dry saline matter, per gallon, 2624 grains, consisting of chlorine 1430, sulphuric acid $125 \cdot 4$, neutralized by the same bases. 
It is difficult to conceive how such a striking and important fact as the impregnation of the waters of the Ocean, upon such a long line of coast, with this deleterious gas, should so long have escaped observation.

Upon searching for evidence of a similar phænomenon having been observed before, I have found in the Phil. Trans. for 1819 , a memoir by the late Dr. Marcet, "On the Specific Gravity and Temperature of Sea Waters in different parts of the Ocean, and in particular Seas, with some account of their saline contents." Out of sixteen specimens which he examined he found one which was brought by Capt. Basil Hall from the Yellow Sea in the Chinese Ocean, which, from the account which he has given, must probably have been as highly charged with sulphuretted hydrogen as those from the coast of Africa; and he observes, "there is something in the development of sulphur in sea water which is by no means well understood."

He also noticed that a specimen obtained by Mr. Schmidtmeyer, going to South America, from lat. $10^{\circ} 50^{\prime} \mathrm{N}$., long. $24^{\circ} 26^{\prime} \mathrm{W}$, had an hepatic smell, and had blackened the bottle in which it was contained.

Since the report, which I had the honour to make to the Admiralty, Sir William Burnett has been kind enough to furnish me with the analysis, by Mr. Garden, of some bottles of water, collected by Dr. Mc William, of Her Majesty's ship Scout, in March 1839, in the river Bonny, of which the following are the particulars:-

1. Water from the river Bonny, taken half a mile inside the mouth, on the 12th of March, 1839, just before the commencement of the rainy season.

Each imperial pint of this water contained 245 grains of saline matter, consisting of the following ingredients :Sulphate of Magnesia

Do. of Lime

Muriate of Magnesia

Do. of Soda

Sulphuretted hydrogen, $\cdot 680 \mathrm{cub}$. in. $(5 \cdot 44$ cub. in. per gall.)

2. Water from the mouth of the river Lagos, lat. $6^{\circ} 20^{\prime} \mathrm{N}$., long. $3^{\circ} 30^{\prime}$ E. nearly.

Each pint yielded 240 grains of saline matter, consisting of the same ingredients as those above mentioned; also Sulphuretted hydrogen, $1 \cdot 844$ cub. in. ( $14 \cdot 752$ cub. in. per gall.)

3. Water from the river Bonny, taken off Ju-ju Point, on the 12th of March, 1839, about one mile and a half within the mouth.

One pint yielded 200 grains of saline substances, as above, and Sulphuretted hydrogen, $\cdot 505$ cub. in. ( $4 \cdot 04$ cub. in. per gall.) 
4. Water from off Grand Bonny, about three miles inside the mouth of the river.

One pint yielded 208 grains of the same salts as above, and Sulphuretted hydrogen, $3.500 \mathrm{cub}$. in. ( $28.0 \mathrm{cub}$. in. per gall.)

These results appear to have attracted no particular attention at the time when they were obtained. The old hypothesis of the corruption of the specimens probably sufficed for their explanation upon this as upon other occasions.

Thus there can be no doubt of the important fact of the impregnation of the waters, upon the western coast of Africa, with sulphuretted hydrogen, to an amount, in some places, exceeding that of some of the most celebrated sulphur springs in the world; and of the injurious effect of such impregnation upon the copper sheathing of ships, you will be convinced by the experiments upon the table.

Were any further evidence wanting, it would be found in the state of the copper of the Bonetta, which lately returned from the coast of Africa, and three sheets of which were sent to me from the Admiralty for examination.

Nos. 1 and 2 were pretty uniformly covered on the outside with a green crust; and on the inside, as evenly, with a black crust of equal thickness. They were very thin in parts, and here and there eaten into holes.

No. 3 was in a much worse state, very thin, and eaten into large holes. In most parts it was easily broken by the fingers; one of the holes, of an irregular shape, measured eighteen inches in length by four inches and a half in width. This sheet was covered with green crust chieily, on both sides; but there were evident traces of the black crust on the inner side.

Upon analysis the black crust was found to consist of sulphuret of copper, and the green of oxy-chloride of copper.

There can be no doubt that the injury to the copper arose, primarily, from the sulphuretted hydrogen. The gas appears to have penetrated to the inner side of the copper, where in Nos. 1 and 2 it has been protected from the further action of the sea water; by which, on the outside, the sulphuret was converted into chloride of copper. This conversion appears to have taken place on both sides in No. 3, from the sea water having penetrated to the under side in consequence of its greater corrosion.

That the establishment of this fact is of some importance in a mercantile point of view, I think I shall be able to convince you by two anecdotes which I will now narrate.

Not many years ago a new copper company set up a smelting establishment and brought their copper to market: some merchants purchased sheathing of them, coppered their ship, 
and sent her to the coast of Africa. Not many months after she returned to this country with the copper in the same state as that of the Bonetta. The merchants said-the coppersmelters were inexperienced hands-they did not know their business-the sheathing was improperly made; and they brought an action against the Company, who defended it.

Upon the trial some of the most eminent scientific men of the day gave evidence that there was nothing in sea water which could produce such rapid decay of the copper, and the jury, in consequence, brought in a verdict for the plaintiffs.

Now contrast this with what has happened to me within the last two months. An eminent copper manufacturer of South Wales, who had heard nothing of the investigations in which I had been engaged, came to me with two samples of copper which he wished me to analyze. The one was of new metal, and the other part of the sheathing of a ship which had just returned from Africa, after a voyage of a few months, the copper being in a state of utter decay. He stated that the merchants to whom the vessel belonged had brought an action against him on the plea that the copper was imperfect, and he wished for my evidence upon the subject, as he well knew that the copper was perfectly good. Instead of entering upon the analysis I gave him a copy of my report upon the waters of the western coast of Africa, which he sent to the merchants, and nothing further has been heard of the action.

But it may perhaps be said that little good will arise from pointing out the evil, unless we are prepared to propose some remedy for it; not that $I$ agree to this, for the existence of the sulphuretted hydrogen is so readily tested, even by the roughest hands, that nothing can be easier than to ascertain and avoid the localities in which it prevails; mutives for which course I shall presently mention, of greater weight even than the preservation of the copper.

But I think that the remedy is certainly within our command. The principle of protection proposed by Sir H. Davy is quite applicable to it, with some additional precantions suggested by this newly-discovered destructive agent, which had escaped his notice.

It is well known that his experiments were conducted chiefly with zinc and iron, as the active elements of protection; and he was led ultimately to the adoption of cast iron, "as the substance which is cheapest, most easily procured, and likewise most fitted for the protection of the copper *."

But this is not the case with regard to sulphuretted hydro-

* Phil. Trans., June 1824, p. 243 ; [or Phil. Mag. First Series, vol. lxv., p. 204.] 
gen; for as you will see by reference to the experiments upon the table, copper is much more acted upon by this substance than iron, the latter being protected by the former; and the fact is, that a piece of iron attached to copper increases the corrosion of the latter.

Zinc, on the contrary, protects the copper not only from the action of the chlorides in sea water, but also from the sulphuretted hydrogen. This I have ascertained by the experiments before you, and you will find that the results are in perfect accordance with the electric order of these two metals in solutions of the hydrosulphurets, as given by Dr. Faraday in his last beautiful number of Experimental Researches in Electricity.

In the table which he gives, iron stands far above copper in electro-negative order, and zinc below it; lead is also above zinc; while in the usual acid solutions both zinc and iron stand below that metal*:

Now I have long been of opinion that the experiment of voltaic protection in the Navy was much too lightly abandoned upon the first appearance of an unforeseen difficulty, and that under circumstances otherwise the most encouraging.

This abandonment, you are aware, arose from what might be called over-protection, by which the attachment of weeds and zoophytes to the ships' bottoms was found to be encouraged. Earthy deposits were formed, and to these the weeds and shell-fish attached themselves.

The remedy for this appears to me to be obvious: instead of keeping the protectors always in contact with the copper, let them be insulated, and let them only be brought into metallic contact when occasion may require. This might readily be done by means of a bolt or bar, forming in one position a continuous conductor between the two metals, and in another breaking the connexion: this might always be at the command of the proper officer of the ship. Nothing could then be easier than to throw off the protection when the ship is in harbour, or in situations particularly liable to deposits; or to restore it upon going to sea, or arriving in latitudes where sulphuretted hydrogen might be found to exist.

But the protectors should invariably be of zinc, which would preserve the copper not only from the effects of sea water generally, but from the more destructive agency of sulphuretted hydrogen, which I shall presently give you my reasons for concluding not only prevails upon the western coast of Africa, but in other situations where it has never yet been suspected. Indeed I incline to believe that it would

* Phil. Trans., 1840, p. 113. 
only be found necessary to use protection in sulphuretted waters, and that the action of the chlorides alone might not be more than sufficient to preserve the copper from deposits.

Another motive for this change may be found in an observation of Sir H. Davy, viz. that a "common cause of the adhesion of weeds or shell-fish is the oxide of iron formed and deposited round the protector. In the only experiment in which zinc has been employed for this purpose in actual service, the ship returned, after two voyages to the West Indies and one to Quebec, perfectly clean. The rudder, which was not protected, was corroded in the usual way*."

But it is impossible not to speculate upon the origin of the deleterious gas which has thus been found to contaminate the sea upon the western coast of Africa, in such enormous quantities through an extent of more than sixteen degrees of latitude, and reaching in places forty miles seawards, making altogether an area of 40,000 square miles in extent.

Volcanic action seems naturally to suggest itself, but is negatived by the absence of any other indications of such action along this line of coast; and I think that I shall be able to convince you, by the evidence of experiment, that the real cause may be found in the mutual reaction of the immense quantities of vegetable matters, which must be brought down by the intertropical rivers, and the sulphates of the sea water.

The idea was suggested to me by a memoir of my friend Dr. Malcolmson, in the Geological Transactions, who speculates upon the origin of sulphuretted hydrogen in the saline lakes of different parts of the world, being "the decomposition of the sulphates in the water by the carbonaceous matter of vegetables." I tested this hypothesis by experiments in the following way :-

On the 2nd of November, 1840, I placed a quantity of newly-fallen leaves in three glass jurs capable of holding about a gallon and a half of water.

No. 1. Upon the first I poured about a gallon of New River water.

No. 2. Upon the second I poured about the same quantity of the same water, in which three ounces of common salt had been dissolved.

No. 3. Upon the third, the same quantity of water, in which three ounces of crystallized sulphate of soda had been dissolved.

The three jars were then placed in a warm chamber, the

* Phil. Trans. 1826, p. 420; [or Phil. Mag. Second Series, vol, i., p. 198.] 
temperature of which varied from about $70^{\circ}$ to $110^{\circ}$, and the water was filled up from time to time, as it evaporated, and the mixture well stirred.

Upon examining them on the 5th of February, 1841 (three months), the following was found to be the state of the jars:-

No. 1 had a very disagreeable odour, but produced no change whatever upon paper soaked in acetate of lead.

No. 2 was perfectly sweet, and possessed, indeed, a rather agreeable odour. It produced no effect, of course, upon the test paper.

No. 3 had a most insupportable sickening odour, much worse than that of pure sulphuretted hydrogen, and instantly blackened paper soaked in acetate of lead, throwing down sulphuret of lead with a metallic lustre.

You will have an opportunity of observing, by the specimen upon the table, that the evolution of the gas is at this moment proceeding with increased energy.

Now, the analysis of sea waters generally, and these analyses in particular, show that a large proportion of sulphates is always present in them, and there is no doubt that extensive mud-banks must be formed at the mouths of the African rivers, within the tropics, consisting chiefly of vegetable detritus, in the exact state which is most favourable to this action.

Since my report to the Admiralty upon this subject, I have seen a paper in the Annales de Chimie for July 1840, by Dr. Amédée Fontan, upon the Mineral Waters of Germany, Belgium, Switzerland, and Savoy, in which he suggests that the presence of sulphuretted hydrogen in those waters may be owing to the decomposition of the sulphates which they contain by vegetable matters, remarking that many of them which contain little of that gas at their sources, acquire more of it by their flow through the soil. There can be little doubt of the correctness of this opinion.

A curious fact has also been brought to my recollection by my friend Mr. Fownes, with regard to a spontaneous change which a solution of litmus undergoes when excluded from the air. It becomes of a brown colour, but still it is not spoiled, for the colour is restored by exposure to air.

M. Vogel (Ed. Journ. 31, 157), who inquired into this curious fact, found that the solution always contains sulphate of potassa, which becomes gradually decomposed with the generation of sulphuretted hydrogen, to the deoxidating power of which the effect is owing. A few drops of sulphuretted hydrogen solution produces the same effect in a few days; the solution becomes brown, but speedily recovers its colour upon 
contact with air. This case is the more interesting, inasmuch as the gas never exists in sufficient proportion to be discoverable by the usual tests; nevertheless it acts in these minute quantities with great energy.

But now a much more important and interesting question than that of the preservation of the copper sheathing of ships forces itself upon our attention, and that is, whether the existence of this deleterious gas in the atmosphere, which must necessarily accompany its solution in the waters, may not be connected with that awful miasma which has hitherto proved so fatal to the explorers and settlers of the deadly shores of Africa; and whether, if so, science may not suggest something to palliate an evil which is so dreadfully opposed to the progress of civilization in those parts.

When this matter was first brought under my consideration, I was surprised that the nauseous smell which must necessarily be evolved from water impregnated with this gas, at so high a temperature as that of the equinoctial regions, had not been noticed. I have in consequence turned to some of the accounts of the late travels in Africa, to seek for evidence upon the subject; and in the narrative of an expedition into the interior of Africa, by the river Niger, by Macgregor Laird and R. A. B. Oldfield, I found the following important observations:-

"'The principal predisposing causes of the awful mortality, were in my opinion the sudden change from the open sea to a narrow and winding river, the want of the sea breeze, and the prevalence of the deadly miasma, to which we were nightly exposed from the surrounding swamps. The horrid sickening stench of this miasma must be experienced to be conceived : no description of it can convey to the mind the wretched sensation that is felt for some time before and after daybreak. In those accursed swamps, one is oppressed not only bodily but mentally with an indescribable feeling of heaviness, languor, nausea, and disgust, which requires a considerable effort to shake off."

Now, these observations were made in the very locality from which some of the first waters which I examined were taken, and nothing more is wanting to identify the cause of the rapid decay of the ship's copper with that of the mortality of the climate.

It has been experimentally found, that so small a mixture as a fifteen hundredth part of sulphuretted hydrogen in the atmosphere, acts as a direct poison upon small animals, and the sensations of languor and nausea, described by Mr. Laird, are exactly those which have been experienced by persons 
who have been exposed to the deleterious influence in small quantities.

The symptoms, in cases where this gas is breathed in a state of concentration, well known to medical men, are sudden weakness, and all the signs of asphyxia : the individual becomes suddenly weak and insensible; falls down, and almost immediately expires. When the exposure has been too slight to cause serious mischief, the individual is affected with sickness, colic, imperfectly defined pains in the chest, and lethargy.

Now, can it be deemed at all improbable, that an agent which is capable of acting with this severity as a direct poison, when mixed in no very high proportion with the atmosphere, should in still less quantities greatly aggravate symptoms of morbific action, which may possibly have their origin in other causes?

In the very expedition, from the account of which I have already quoted an extract, a circumstance occurred which is almost an experimental confirmation of these views. The first sickness and death in that expedition began at Cape Coast Castle; three died before entering the river, and the great mortality took place before they reached Damuggoo at the extreme upper end of the Delta, where they only arrived after a voyage of thirty-six days, from the 11 th of October to the 16th of November, or twenty-seven from their entrance of the river Nún.

Now it is worthy of remark, that just before entering the river, in "breaking out" the hold to lighten the vessel, it was discovered that the cause of a "disagreeable vapour, from which they had long suffered, was, that the bags containing the cocoa had rotted, and the cocoa had fallen into the salt bilge-water and there become putrid." Here, then, were the very ingredients for generating sulphuretted hydrogen to a great extent; the lamentable consequence has been before alluded to, namely, three deaths before reaching the river. There can indeed be no doubt that the disagreeable effluvium of bilge-water, which has been carelessly left undisturbed for a long time, is owing to similar decomposition.

It is doubtless the same circumstance which renders Mangrove swamp so notoriously pestilential in all parts of the torrid zone. The tree only thrives in salt water, and its decayed foliage is admirably adapted to act upon the sulphates; and it accounts for the observation, that malarious fevers diminish as we recede from the coast, although swamp and rank vegetation may still prevail.

The close investigation which $I$ have since given to the 
subject, more and more convince me that the worst cases of malaria are generally connected with the presence of sulphuretted hydrogen.

There is a paper in the twenty-ninth volume of the Annales de Chimie, p. 225, by Signor Gaetano Giorgini, which offers the strongest possible confirmation of my opinion.

"The observation of Signor Giorgini has been drawn to the state of the atmosphere in the neighbourhood of certain marshes on the borders of the Mediterranean; and by refexence to historical data, and various documents, he has proved the great importance which attaches to the circumstance of their being, at times, in communication with the sea, so as to have a mixture formed between their waters and that of the sea. Both ancient and modern authors have announced the fatal effects produced in the neighbourhood of marshes by such mixture, and a local belief of the same thing is very common and strong.

"On the south of the Ligurian Apennines is a marshy shore, bounded on the west for twelve miles by the Mediterranean, on the south by the river Serchio, and on the north by the river Frigido, a torrent commencing at the foot of the Apennines, in the state of Massa di Carrara, running three or four miles over the land, and then falling into the sea. The plain is from two to four miles wide, and is traversed by a few short torrents or streams; among these are the rivers Camajore and Pietra Santa, which clivide the plain into three separate basins. The rain and spring waters which flow into the three basins mentioned, are slowly discharged into the sea by natural or artificial canals, penetrating the sand-bank, which exist on the sea-side.

"The level of these stagnant waters is between that of high and low water in the neighbouring sea; there being but little difference between these two points in this part of the Mediterranean. In this state of things, formerly, when the waters of the sea arose from any circumstance (unless the waters of the marshes were very high), they used to return up the ditches, fill the basins, and inundate the country to the foot of the mountains; and with a north-west wind, the waves used to penetrate with force to the interior. The mixture of fresh and salt water thus formed, and which, in summer, was rarely changed, became corrupt, and spread infection over the neighbourhood of the most destructive kind.

"In this way the effects of the malaria were reproduced annually in the neighbouring country, with all their peculiar horrors: the population, though small, presented feeble infants 
and diseased men, old age being unknown there. All attempts to avoid the scourge, by living on the hills, or in the interior, and frequenting the plain when the business of cultivation essentially required it, were vain; they fell victims to the extensive influence, and such being the effects upon the inhabitants of the country, much more rapidly did a stranger suffer from the deleterious atmosphere; one single night, in the months of August and September, causing inevitable death to the incautious traveller who should stay so long in this infested country.

"Such was the state of things until 1741. Previous to that time, Gemignano Rondelli, Eustachio Manfredi, and Bernardino Zendroni had successively insisted upon the necessity of excluding the sea from these marshes; and, in 1740-41, a sluice, with folding doors, competent to give emission to the waters of the marsh, but prevent the sea from entering, was constructed at the mouth of the Burlamacca. The most complete and unexpected success immediately followed upon, and has continued with, this work. The year after its completion there were no appearances of the terrible maladies which previously appeared every year. 'The inhabitants soon recovered health, and the land being very fertile, the population rapidly increased, and is increasing at this moment. Viareggio has become a considerable town, and so completely has all suspicion of its insalubrity disappeared, that the first families of the city of Lucca have for years built their summer seats there. Notwithstanding the success of the precautions taken at this part of the coast, the neighbouring parts were long left a prey to the destroying influence of the mixed marsh-waters; and the inhabitants around the basins of Motrone and Perotto were not considered until the year 1804. In the years 1809 , 1810,1811 , similar means were taken, with the best effects to the inhabitants of Montignosso and the vicinity; and, in 1812 , a sluice was constructed on the Cinquale, which perfected the arrangements in this part, and made a large portion of country equally healthy with Viareggio. 'To complete the arrangement, it was now only required to guard the ditches of Motrone and Tonfalo with sluices; the former was finished in 1819 , and the latter in 1821 . Since that time the diseases of malaria have ceased so entirely at all points, that no other dangers are now incurred regarding the insalubrity of the atmosphere than such as may arise from neglect of these sluices, which the inhabitants of the country should regard as their palladium."

I should weary you were I to multiply examples of the 
existence of the worst forms of malaria in places which we now know combine all the necessary circumstances for the generation of sulphuretted hydrogen.

In Mr. Darwin's interesting Journal of the Voyage of the Adventure and Beagle, he speaks of several such places, especially in Peru, in connexion with the well-known effects of miasma, but not with any suspicion of the real origin of the evil. He mentions repeatedly the efflorescence of the sulphates of magnesia and soda upon the soil, and that the mud of the saline lakes is "black, and had a fotid odour." The inhabitants suffer in such situations from the worst attacks of ague. He remarks, p. 447, "The attacks of illness which arise from miasma never fail to appear most mysterious. The miasma is not always produced by a luxuriant vegetation with an ardent climate; for many parts of Brazil, even where there are marshes and a rank vegetation, are much more healthy than this sterile coast of Peru."

"So difficult is it to judge from the aspect of a country whether or not it is healthy, that if a person had been told to choose within the tropics a situation appearing favourable for health, very probably he would have named this coast."

Its peculiarity consists in the saline efflorescence upon its soil, of which the sulphates of magnesia and soda constitute a very great proportion.

May not the jungle fever in India depend for much of its malignity upon the same cause? The soil in many parts abounds not only with the nitrates of potassa and soda, but the sulphates of soda and magnesia; these become washed down by the periodical rains, and mingling with the decaying leaves, the mutual reaction takes place.

Is it not worthy again of the most exact inquiry, whether the fevers which periodically afflict the cities of New York and Charlestown, in America, may not be connected with the mixture of animal and vegetable substances with the sea water in their lower districts, where they usually originate; and whether an attentive examination will not prove, that the same impregnation of sulphuretted hydrogen, which we have established upon the African coast, exists at the mouth of the vast rivers of the American continent? Indeed I have been informed by an officer high in the naval service, that during the war instances of the rapid decay of ships' copper, similar to that upon the African, were noticed upon the West-Indian station.

To bring the matter nearer home. Is it impossible that. the minor insalubrity of parts of our own coast, such as that of Essex, may have some reference to the same causes acting

Phil. Mag. S.3. Vol. 19. No. 121. July 184.1. 


\section{Prof. Daniell on Sùlphuretted Hydrogen in Sea Water.}

in minor degrees. The mud of the river. Thames may surely produce the same decompositions of the sulphates in the sea water as that which we have traced in other places. I find that there is a prevalent idea, which deserves investigation, that the ships in the Medway are liable to greater waste of their copper than those at Woolwich, or other places on the Thames.

Within the past week $I$ have seen in the number of Liebig's Annalen for January last, that Dr. Clemm examined some water taken up in December 1839, in the open sea off Barmouth, North Wales; also from Aberystwyth and 'Tenby in South Wales; and he observes, "In some of the bottles from the English coast the large proportion of sulphuretted hydrogen was very striking: both in smell and taste it was converted into a strong sulphurous water." He seems to think that the accidental presence of some of the sealing-wax with which the bottles were closed, may have had something to do with the generation of the gas.

By the kindness of Sir Isambard Brunel, I have been favoured with the particulars of a very remarkable phænomenon of this kind, which attended the progress of the Thames Tunnel, and which proved of great annoyance, and was the cause of great suffering to some of the workmen. This was the evolution of great quantities of carburetted hydrogen mixed with sulphuretted hydrogen gases. In 1837 the smell was extremely foetid. "It frequently rushed out from between the small boards of the shield, used to scour the ground with great force, bursting into a flame, which sometimes extended over some feet, and was generally accompanied by a loud roaring or hissing noise."

In 1838 , the sulphuretted hydrogen was unaccompanied by the great quantity of carburetted hydrogen with which it had been previously mixed, but its effects upon the men were very severe, producing sickness, giddiness and fainting, pains in the head, and in one case delirium.

The source of this enormous production of gas may probably have been the deposits of animal and vegetable matters in the mud of the river, acting however by the sulphates, which are contained in the former, in a manner perfectly similar to that which we have traced to the sulphates in the sea water.

And here again it may be asked, as with regard to the injurious effects of sulphuretted hydrogen upon the copper of ships, can science indicate a remedy, as well as point to the cause of the disease? And again I would reply, that by furnishing an easy method of detecting the evil, she furnishes you with timely warning to fly from the infected regions. No vessel should be allowed to cast anchor or linger in sulphu- 
retted waters. But if paramount duty should oppose itself to such a course, we have a certain remedy to propose. You have seen how instantly chlorine destroys the gas. Chlorine and sulphuretted hydrogen cannot coexist together. Plentiful fumigations of chlorine would therefore infallibly prevent the deleterious effects; and the antidote is at once cheap, and incapable, under proper management, of producing any injurious effects to counterbalance its advantages.

The Lords of the Admiralty have received these suggestions with indulgence, and have given instructions to their cruisers upon the African coast to test the waters at regular intervals. They have also abundantly supplied the African expedition with the means of chlorine fumigation; and I have the gratification of knowing that the views which I have now had the honour of submitting to you, have tended to give confidence not only to the gallant band who have devoted themselves to one of the most disinterested enterprises which ever emanated from pure Christian charity, but to the numerous friends who wait the result with anxiety.

II. Abstract of recent Researches on the quantity of Heat evolved in Chemical Combination, particularly those of MM. Dulong and Hess.

FARADAY baving established the law of definite electrolytic action, and thus connected together the two principles under which scientific chemistry at the present day is organized, the abstract and the numerical, the electro-chemical theory and the law of equivalents, it became an interesting point to examine whether affinity possessed the same definiteness of character in relation to other physical agents, and especially to heat, the influence of which on affinity is even more remarkable than that of electricity, and with whose operations indeed chemistry itself, until a comparatively recent date, was identified.

Investigations tending to this end had been long since entered on. The measurement of the quantity of heat evolved in combustion was, independent of all relations to scientific theory, a problem of such technical importance, that it has occupied from time to time all those philosophers who devoted themselves to that branch of science. Their results, frequently discordant, but stili often useful, have been considered, especially those of Despretz, as indicating that the heat evolved was proportional to the quantity of oxygen which entered into combination.

For some time before his death, M. Dulong had been occuC 2 